\title{
9 Maa Democracy, Development and Alternative Realities: an Open Letter ${ }^{1}$
}

Dear Robert,

I'm sorry that it has taken me so long to acknowledge your kind gift of Whose Reality Counts? (Chambers 1997), and that I have evaded any answer to your question until now. Attempting this takes me back to our very different types of involvement as novices among the Samburu around 1960, when I as an anthropologist found our conversations invigorating and valued your hospitality as a District Officer and your encouragement to voice my criticisms of the colonial record. A key interest that we shared at that time has a bearing on your book. This concerned the nature of decisionmaking among the Samburu, and this was amplified when I later turned my attention to their cousins, the Maasai and also to the Chamus, where our paths indirectly crossed a second time.

\subsection{Public Consensus and Private Anxieties}

In Whose Reality Counts?, your depiction of Participatory Rural Appraisal (PRA) involves 'changes and reversals of role, behaviour, relationships and learning' shared by the whole community and extending to advisers in a sustained attempt to resolve problems of rural development. PRA facilitators do not dominate. They sit down, listen and learn, encouraging people to express their own realities. This conjures up memories of formal debates among Samburu elders. These allowed all points of view to be expressed, but only one at a time, inhibiting private disputes or sustained interruptions. Their discussions would take place in the shade of a large acacia tree, and this provided an analogy for the process of arriving at any decision. They pointed out that the branches of this tree were like the different views expressed by various elders on some vexed topic, while the trunk was a meeting point of these branches, binding them together in a unanimous compromise.

Any elder could speak at these assemblies, standing up while the others remained seated on the ground. But he had to obey the rules of procedure, taking his turn, addressing the issue, and making a coherent contribution. While ideally he could voice any opinion without interruption, others could call on him to sit down if they felt that he was rambling or disagreed with him strongly. On contentious issues,

1 An earlier version of this chapter has been published under the title 'Foxes and Hedgehogs - and Lions: whose reality prevails?', in Cornwall, A. and Scoones, I. (eds.), 2011, Revolutionizing Development: reflections on the work of Robert Chambers. London: Earthscan. (pp. 45-51). I am grateful to the publisher for permission to reproduce it here. 
interruptions could lead to a groundswell of dissent and even to episodes of unruly shouting between rival factions.

The most influential elders were those with the skill to frame an argument that sought to resolve diverging interests with an acceptable compromise. An elder who rose to the occasion would command the attention of the assembly, eloquently wielding his stick to make each point in his own time, with the oratorical use of extended pauses and repetitions to hold his audience. The assembly would argue the various points of view with no fixed agenda or limitation on their time. The debate on any topic would continue until they resolved their difference and reached a binding compromise by common consent, or overwhelming pressure, or just exhaustion. The decision would then be confirmed by invoking God's blessing. This was led by a member of the oldest age-set present, even if he had to be woken up with no clear grasp of what had actually been agreed. The sense of unanimity and the blessing gave the occasion an irrefutable authority.

In your book, you adopt Archilochus's metaphor, contrasting creative foxes with fundamentalist hedgehogs. ${ }^{2}$ In this vein, the Samburu elders were behaving like foxes, with many ideas that contributed towards the resolution to their problem. This may fall short of the PRA ideal in that these debates excluded all women and younger men, but it does express a compromised version and reflects the embedded gender and age divisions that characterised Samburu society. In my mind's ear, I can hear Samburu elders pointing out that their wives are merely hedgehogs (injolis) with just one big idea - a fundamentalist desire to keep having children linked to a widespread concern for their fertility - while they, the elders as foxes (isiron), have a broader and more mature understanding of the world with robust ways of thinking and responding. This displays an alternative fundamentalism, of course, regarding their wives as 'children', and disregarding any contribution that women's points of view can make towards the debate. ${ }^{3}$ However, the elders do add that they have an overriding responsibility for the well-being of their 'children' and go hungry if necessary to make sure that these dependants are fed.

Samburu women's anxiety over their fertility is expressed in their dancing, and this is a theme that has been reported more widely in the region and other parts of Africa. This touches on another area of concern: population growth in underdeveloped areas. You note this, but as a neo-Malthusian, I am less reassured by your evidence of some kind of balance between population growth and economic development. ${ }^{4}$ In East Africa, the official 2012 estimate for the annual growth rate of population was $2.44 \%$. This may seem containable at first sight, but it implies a doubling of the human population every 29 years with no end in sight. Even in areas as remote as Samburu, I

2 Chambers 1997: 163.

3 Cf. Chambers 1997: 88.

4 Chambers 1997: 24-6, 31. 
estimated an annual growth rate of $2.3 \%$ in 1973 for a clan that by definition excluded immigrants. ${ }^{5}$ As a global phenomenon this presents an ethical Pandora's Box. World powers may confer over climate change or international financial crises, and they may just conceivably have some impact in sorting these out. But can you conceive of a situation where there might be some global consensus over population limitation? You note that poorer sectors adopt a robust strategy to cope with their poverty in the long-term. ${ }^{6}$ Yet one of these robust approaches is to aspire to large families as a safeguard for their old age. To assume that the pace of economic development will match population growth is speculative, especially in a world that is running short of fossil fuels and threatened with climate change. Redistributing global resources could buy valuable time, but it would not address the basic problem. Nor can we safely assume that birth rates and poverty traps are set to diminish over time. With population growth at this rate, the escalation of man-made disasters seems set to continue. At a local level, I wonder how a PRA facilitator would handle a discourse on this issue. Public debates do not necessarily dispel private anxieties.

\subsection{The Institutional Context of Decision-making}

Turning to the Maasai, decision-making follows a similar pattern to the Samburu, but on a grander scale. The sense of age-set loyalty among the Maasai is not compromised by clan divisions as among the Samburu, and this can lead to bitter disputes between age-sets relating to promotions up the age ladder. During their years at their warriorvillage, Maasai moran are encouraged to cultivate a debating finesse as a key to their 'warrior' discipline and as a training for consensual action when they become elders. With elderhood, the key virtue remains as loyalty to their age-set. A defaulting age mate who fails to comply with expectations may be punished by slaughtering one of his finest oxen or even by an age-set curse. If just two age mates approach a third with a reasonable request, they represent their age-set at large and he should comply. It would be a disloyalty to his age-set to do otherwise. When an elder is summoned by his age mates to lend his support by attending some gathering, he 'dare not' refuse. If a particularly astute member is nominated by acclaim to represent a group of age mates or is asked to lead a delegation on some issue, there may be an implicit kudos or coyness in accepting this role, but again the expected response is that he 'dare not' refuse.

At a more formal debate, his role as a representative gives a man considerable authority to persist in asserting his case in contention with others, including representatives from rival pressure groups. In Maasai terms, he is a 'feather'

5 Spencer 1997: 214.

6 Chambers 1997: 175. 
(enkopiro). This term refers to the ostrich feather head-dress that encircled the head of a Maasai moran, rather as the collectivity of representatives surround the eloquent and supremely influential figure of the spokesman for the age-set: their 'head'. In a debate, the spokesman should be the last to express an opinion, having weighed up all the arguments. His skill is to bring together these diverse views in the course of debate, without declaring his hand too soon. He is expected to listen, especially to the 'feathers', and then to steer the debate towards a binding consensus. The spokesman (or 'head') chooses other age mates as his aides ('necks') to support him in his general task of governing his age-set. But the Maasai insist that real power lies with the representatives ('feathers') who can hold the spokesman to account if they consider that he falls short of their democratic expectations, and even replace him in the final resort.

A point to bear in mind is that in the more casual discussions and gossip of daily life, men of influence are priming themselves with relevant information that underpins their performance on the more formal occasions. The hierarchy of roles on these occasions provides an institutionalized framework, both for arriving at wideranging decisions relevant to a broad community of interests, and for acting on them afterwards - considering differences of opinion in the first instance, and inhibiting dissent after a decision has been reached.

You describe PRA as a means of arriving at such decisions after informed debate, but does PRA build on locally established institutional practices to arrive at and pursue resolutions? Quite apart from subversion, can there be a Hawthorne effect once the facilitators have left the scene, with participants reverting to their old institutional practices and personal concerns for their own interests? Your book criticises the institutional assumptions and practices of those in power and a table refers to building up local institutions in the longer-term, but you appear to overlook the resilience of existing local institutions in community dynamics and the necessity of working through them to facilitate development. ${ }^{7}$

With respect, while Whose Reality Counts? is disarmingly self-critical, it reads as though PRA is seeking to wipe the slate clean before building up a new rapport, overlooking the rich and creative significance of local institutions that are themselves products of local cultures and capable of modifying with changing circumstances.

Three examples from the East African pastoralist region demonstrate the scale of oratory in local decision-making.

First, a raw form of democracy has been reported among the Karimojong of northern Uganda, where any forceful elder can try to impose his views in a debate. Having emerged as a local leader, he may order persistent objectors to leave the meeting, provoking a minority to vote with their feet and to form a rival faction with their own spokesman and debate. If this movement threatens to wrest the initiative,

7 Chambers 1997: 57, 85, 115, 221-2. 
the local leader is expected to climb down and reassess his views in order to remain within the mainstream of discussion. In this example, the thrust towards consensus overrides the clash of personalities. ${ }^{8}$

Second, a particularly sensitive analysis of elders' debating is by David Turton in relation to the Mursi of southern Ethiopia, and it draws attention to the modulating rapport among elders in reaching for agreement on any problem. The most influential Mursi elders are those with a flare for piecing together a forceful argument that assimilates different points into some imaginative synthesis, overriding parochial interests. Such men have to cultivate their reputation, or popular regard will shift to those who outshine them, especially ambitious younger men. Each debate has the potential to modify the contours of influence, based on attendance and performance. Each speaker needs to cultivate his audience. He should only interject at a point when they are ready to listen, and then hold their attention with a terse style and subtle allusions that make a significant contribution toward the discussion. He should then finish at a point of his own choosing, before he is hassled by a rising tide of interruptions. If he attempts to intervene prematurely when attention is still focused on another speaker, or too often, or with too little to say, then he will lose face. No individual is indispensable, and no-one is expected to arbitrate between conflicting views. Rather there is an implicit process of peer review with the most influential contributions emerging towards the end, bringing together the strands of argument and reducing the need for further discussion. ${ }^{9}$

Finally, the most imposing debating arena in the region is among the Oromo in the Ethiopia-Kenya border area. Successive Oromo 'age-sets' enter the ruling gada 'age grade' for periods of eight years and then retire. During each gada period, an array of office holders are nominated to take responsibility for resolving all forms of conflict and dispute; and midway in this period, a massive pan-Oromo assembly is mounted to consider intractable problems. No aspect of customary law is immune from scrutiny on these occasions, and the debating is geared towards updating tradition in order to adapt to the realities of change. This example draws attention to the adaptability of a highly structured institution. ${ }^{10}$

\subsection{Institutionalised Adaptability}

The robustness of indigenous decision-making leads me to consider the Chamus, to whom you also have drawn attention in relation to the implications of a top-down

8 Dyson-Hudson 1966: 223-4.

9 Turton 1975: 171-8.

10 Legesse 1973: 81-98. 
approach to development in colonial times. ${ }^{11}$ Here my focus will be on the Chamus tradition of the opposite: an indigenous process of bottom-up development.

Historically the Chamus have experienced a string of changes in their social organisation associated with in-migrations and an increasingly mixed economy based at first on irrigation agriculture, then with trading their surplus, then agropastoralism, then dependency on famine relief after the breakdown of their major irrigation system, and finally the response to new opportunities following Kenya independence. The significant point here is not the details of how these changes came about, but the mechanism whereby the Chamus elders responded to these changes.

Developing and maintaining the Chamus irrigation system required a collective discipline, and this was achieved through a Council of elders, which consisted of all household heads. Attendance at their meetings was compulsory, and any breach of a decision by the Council was a punishable offence. The Chamus word for their Council was olamal, which corresponded to the Maasai term for a ritual delegation whose requests must never be refused. In coining this term, the Chamus seem to have emphasised the compulsive element that followed from the sanctity of Council rules.

The Council provided the opportunity to pool creative strands of understanding through open discussion. The oratory of more persuasive elders may have had more influence in the final resort, but still their debates stimulated a process of selection by popular acclaim. As among the Samburu and Maasai, deliberations only concluded when a consideration of all points of view led to a working consensus. Unanimous agreement could then be achieved with a degree of coercion over any reservations, or through sheer exhaustion. The agreement was then binding on everyone through a blessing.

According to Chamus elders, each successive transition in their economy was mulled over by their Council in order to arrive at a united course of action; and each successive age-set is remembered for its contribution to this evolving process while they were active moran, often playing a part in introducing innovations. However, it was the Council of elders and not the moran that steered the process of adaptation, maintaining an overarching control, with the age-set of moran available to support their decisions when necessary. The richness of Chamus oral history was matched by the sanctity and practicality of their system. Once again, the implication here is of an indigenous institution for decision-making, backed by public opinion in order to maintain their system while adapting to new realities.

Your critique of top-down development among the Chamus raises an awkward question. How far can local cultures and institutions adapt to any development agency that espouses different premises, and vice versa? Suppose the agency requires women and younger men to be consulted and values their input, whereas this is alien to the local elders, who regard themselves as the custodians of their society and way

11 Chambers 1973. 
of life. ${ }^{12}$ Reverting to Archilochus's metaphor, the elders see themselves as shrewd foxes, and any ideological challenge to their custodianship may be regarded as the fundamentalist bigotry of some narrow-minded hedgehog (and again vice versa). To put this another way, can there ever be a totally unblinkered culture-free approach to PRA from above or below? Any institution or interested party must have some basic premises and these imply a fundamentalism. Coining the idiom of your book:

Can there be any solution

Without some institution?

Or any institutional promise

Without a fundamental premise?

\subsection{The Problem of Subversion}

As against the metaphor of hedgehogs and foxes, we may shift the focus to consider Pareto's foxes and lions. This involves a switch from a question of insight and understanding to one of integrity, providing a different slant on the character of the foxes. Let us call these respectively wise foxes after Archilochus and sly foxes after Pareto. For Pareto's sly foxes, their wide variety of experience and perceptiveness feeds their cunning in the devious pursuit of self-interest. In this metaphor, sly foxes are portrayed as scheming innovators and are opposed to lions, who are essentially loyal to broader social ideals and strong enough to pursue these. But faced with the complexity of change, lions are vulnerable to the scheming manipulations of sly foxes. Lions are the backbone of an establishment, but in effect they have the underbellies of hedgehogs.

This switch of metaphor is well illustrated in Peter Little's penetrating study of more recent development among the Chamus. ${ }^{13}$ Little traces the penetration of capitalism into the Chamus economy following the privatization of land in Kenya. This gave rise to a new generation of entrepreneurs - the Paretovian sly foxes - who systematically acquired land and stock from impoverished Chamus, and then exploited them further as cheap landless and stockless labour. The discipline of the age-set system gave way to new inequalities that were perpetuated through generations within each family.

Turning to your comments on the success of PRA, this seems to assume that participants collaborate as wise foxes and then maintain their PRA gains as trusting and trust-worthy lions. ${ }^{14}$ Plato's Republic was very close in some ways to your model

12 Chambers 1997: 88, 213-4.

13 Little 1992.

14 Chambers 1997: 199, 208-9. 
and sought to cope with a more complex range of basic personality types than we have considered here. Plato's solution was in effect to take those warriors/moran that had proved to be lions or wise foxes, and then, when they retired to elderhood, to sit them at the high table as a privileged elite over other retirees who were unsuited to govern. Your model, on the other hand, is slanted towards a universal concord of good will, with no high table and suppressing or ostracising any suggestion of rival agendas. This may be compared with two classics on Maa society that suggest a more cynical view of democracy. Philip Gulliver's (1963) book on social control among the Arusha portrays them as sly foxes that resort to lies and subversion as they seek to build up alliances in order to settle their disputes on the one hand while also trying not to become involved in their allies' disputes on the other. This approach echoes Merker's (1904) repeated assertion that the Maasai follow the principle of pursuing self-interest with the axiom that 'Might goes before Right'.

Yet surely, all these metaphorical guises - sly foxes and hedgehogs included - are aspects of our persona, shifting with context. You dwell on a popular criticism against Freud. ${ }^{15}$ But it was Freud who led us to understand the manipulative infantile sly fox that lies buried in the human condition, and indeed the ambiguities of character more generally that are inadvertently revealed in our behaviour. Frustration may tempt wise foxes to become slyer, and it may turn lions into hedgehogs. Sly foxes in youth may become lions and pillars of the establishment as they mature, and then staid hedgehogs as they age in a changing world. And indeed this resembles the Maasai elders' view of their age system, with moran cast as sly foxes, filching their stock and seducing their young wives. Maasai women in general reverse the order, regarding moran as glamorous lions and their husbands as sly foxes. In Gulliver's study of the Arusha, elders confront one another as sly foxes over lineage land disputes and in their shadow-boxing over age-set promotions, but then they become the lions of the age-set establishment in maintaining social order. Note the institutional context that provokes the style of response: family interests on the one hand as against age-set loyalties on the other. It is because we are so vulnerable to the many sides of our personality that the very basic teachings that lead us towards adulthood are couched in terms of the fundamental strictures of hedgehogs that you criticise (and Plato extols). ${ }^{16}$ These are aimed at confining some of our more basic instincts and fostering the lion and wise fox within us to mature.

15 Chambers 1997: 77-8, 82-3.

16 Chambers 1997: 59-62; Spencer 2003: 242-6. 


\subsection{Conclusion: The Clash of Fundamentals and the Pragmatics of Compromise}

This raises further awkward points. Your model presumes an inherent and thoroughly open-minded altruism, free from cultural assumptions or self-seeking motives. ${ }^{17}$ But can a PRA inspired transition that has been achieved in a general spirit of compromise survive in the longer term? Pareto's analysis of history envisaged the rule of lions as vulnerable to the manipulation of sly foxes, who replaced them as the governing elite until they in turn were overthrown by a re-emergence of lions in an endless cycle. In the Maasai model, aggressive younger age-sets replace ageing senior age-sets until they too age and are replaced. But can this guarantee a continuity of the original PRA ideals, especially as times change and new leaders emerge with their own agendas? ${ }^{18}$

Again, how would a new system cope with a major crisis of confidence? Your suggestion that PRA innovations are infectious and build on one another positively seems reminiscent at first sight of the growth of Maasai group ranches. ${ }^{19}$ From diffident beginnings, these seemed to have growing popularity among the Maasai. However, their boundaries were challenged at critical times by the pressure for flexibility in the face of drought and growing populations, and these boundaries would give way to the overarching principle that all their land belonged to all Maasai. Eventually, it became clear that the increasing attraction of new group ranches had been prompted by a fear of losing newly acquired land rights if they did not join. Here, there was a clash of two fundamental principles: traditional claims in sharing land as against the environmental need to protect this land from overgrazing.

The success of PRA initiatives described in the pages of your book brings hope that life in rural areas stands a chance of adapting locally to environmental problems, even if attempts at higher levels have failed to produce a solution. PRA is clearly in tune with upbringings that seek to restrict our very basic self-centred instincts in order to participate as social beings in problems that are ultimately social. This points towards a collective compromise with reality, expressed in the image of a Maasai warrior's feather head-dress. While local institutions are capable of changing, they are embedded in the local cultures that provide their local legitimacy and are the best hope for containing the sly foxes. Similarly, the ultimate legitimacy of development agencies depends on their keeping their own sly foxes at bay. Could you envisage a PRA that is equally prepared to meet these existing institutions half-way in a spirit of compromise? Would you be prepared to respect some of their fundamentalism in order to legitimise the search towards some tangible result? Each step forward is a compromise with harsh reality, and in answer to the question posed in your title,

17 Chambers 1997: 13, 208-11, 215, 234.

18 Chambers 1997: 189, 217.

19 Chambers 1997: 133, 196, 199, 206, 209, 223. 
Whose Reality Counts?, I suggest that this compromise is the post-colonial reality that really counts.

Will age-set institutions play any role in these compromises? The strength of age systems is that they encourage a discipline that favours lions and wise foxes. The weakness of a world governed by market forces and rising populations is that this world becomes a playground for sly foxes as age related inequalities are outmoded by inequalities between families, and age-set systems lose their teeth.

In this vein, no doubt Maa traditions will ultimately become extinct just as social anthropology will become a branch of the history of non-western institutions. Nevertheless, the record of these traditions can provide a rich heritage for the Maaspeaking peoples and in the final resort for all of us. The study of the decreasing number of societies organized around the concept of age-sets and the inevitability of ageing helps us to respect these societies and to appreciate how this topic fits into a wider understanding of human institutions.

May your book earn you a more effective Samburu blessing than I could possibly hope to emulate, my old friend.

Paul 